\title{
アルミン酸ソー夕溶蔽の祭気圧
}

\section{VAPOUR PRESSURES OF SODIUM ALUMINATE SOLUTIONS}

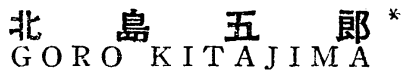 \\ 三 次 MITSUGI
}

There are many reports on researches concerning the equilibrium of sodium aluminate solutions, but few reports have been published from the thermodynamic point of view. because theyare metastable and easilt over saturated with respect to $A 1(\mathrm{OH},)_{3}$. In order to contribute to this part of research, the following experiments and calculations of the equation were carried out.

One of the writers (Kitajima) obtained the values of vapour pressures of caustic soda solutions and sodium aluminate solutions (containing a small amount of impurities) by the pressure reduction method with variations of temperature $40,60,80,100^{\circ} \mathrm{C}(\mathrm{t}) ; \mathrm{Na}_{2} \mathrm{O}$ concentration $100,2 \mathrm{CO}, 300 \mathrm{~g} / 1$ (n) ; and $\mathrm{Al}_{2} \mathrm{O}_{3} / \mathrm{Na}_{2} \mathrm{O}$ mol ratio $0-0.6(\mathrm{~m})$.

From these observed results, the other writer (Mitsugi) obtained the following experimental equation with the above variables $t, n$, and $m$. The experimental values of the vapour pressure of caustic soda solutions, however, were corrected according to those based on the Int. Crit. Table and the relation was studied from the temperature variation of the activity of water.

$$
\mathrm{P}=\mathrm{Pw}-4.02 \cdot 10^{-3} \epsilon^{0.04317 \mathrm{t}} \cdot \mathrm{n}^{1.149+3.72 \mathrm{t} \cdot 10^{-3}-2 \cdot 9 \mathrm{t} 2 \cdot 10-5}-3.24 \mathrm{~m} \mathrm{e}^{0.0223 \mathrm{t}-6} \mathrm{mnt} \mathrm{t}^{4.8 \times 10^{-11}}
$$

Pw shows the vapour pressure of pure water at $t^{\circ} \mathrm{C}$. As to the accuracy of the equation, calculated values for caustic soda solutions of various temperatures and concentrationes were compared with those based on the Int crit. Table, and the accuracy was found to be $\pm 2 \mathrm{~mm} \mathrm{Hg}$, and in case of sodium aluminate solutions, the standard deviation between the observed values was calculated for solutions of various temperatures, the result beingr as follows ;

\begin{tabular}{|c|c|c|c|c|}
\hline${ }^{\circ} \mathrm{C}$ & 40 & 60 & 80 & 100 \\
\hline$\sigma \mathrm{mm} H g$ & 1.1 & 1.8 & 3.0 & 4.6 \\
\hline
\end{tabular}

\section{1. 緒咅}

アルミン酸ソーダ浴液は㐾来研究された所に体札ば、 不安定系て $\mathrm{Al}(\mathrm{OH})_{3}$ に就き過领和の状態を出現し易

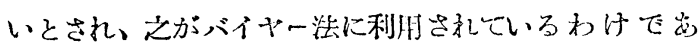
るが、パイナー法に於けるボーキサイトの溶解及びアル

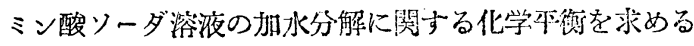
事は反応速度の問題と相まつて、アルミナ製造上重要な 問題と思はれる。然し、本平衡に留しては從采多くの垁

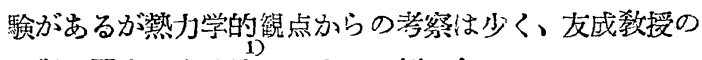
本衡に関与る実験等その少い一例だある。

所で本平街は次の如く畫かれる。 $\mathrm{Al}(\mathrm{OH})_{3}+\mathrm{NaOH} \underset{\leftarrow}{\mathrm{NaAlO}} \mathrm{Na}_{2}+2 \mathrm{H}_{2} \mathrm{O}$ その本衡恒数は $\mathrm{Al}(\mathrm{OH})_{3}$ の活量が一定と見なされる
35、

$$
\mathrm{K}=\mathrm{aNaAlO}_{2}\left(p / p_{\mathrm{w}}\right) \div / \mathrm{aNaOH}
$$

但し、 $\mathrm{aNaAlO} 2, \mathrm{aNaOH}$ は夫љ $\mathrm{NaAlO}_{2}, \mathrm{NaOH}$

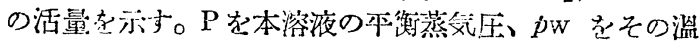

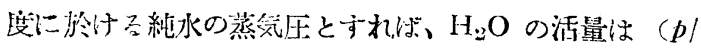
$p w)$ 〔氺められる篦である。

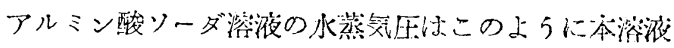

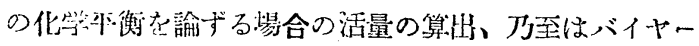

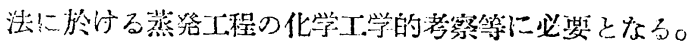

\section{2. 蒸気任の測定}

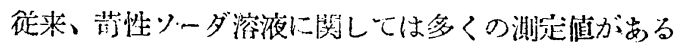
が、アルミン酸ソーダ溶液に就いては、前述の友戍郄授

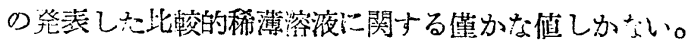

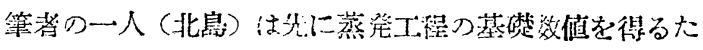

*日本轻金楀筷式会社清水工場試験課長

Nippon Light Metal Co., i.td. Shimizi Plant

1) (工化、45669, (昭 17)) 


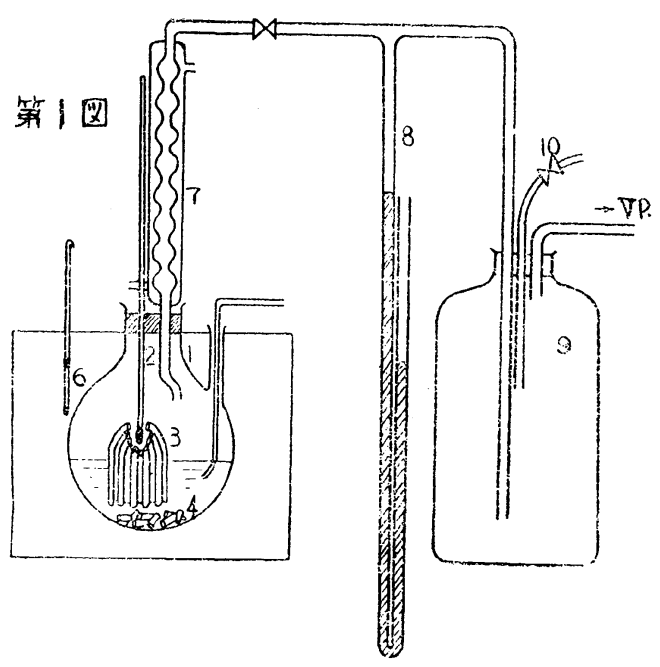

区中武性ソーダ溶液に関する実線は Int. Crit. Table に挙けられた Antroff \& Sommer 等の侹に基き広範 圈にまとめられれ奏浿值に就いて学位换算をして亦した

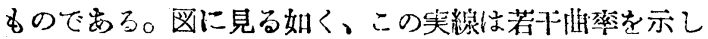
北島の値と多少相違する。

但し、gr per Liter (E/T), weight \% (w) 及心゙ gr olute per 1,000gr solvent $(\mathrm{h})$ の間の単位換算は次式 に依り求めた。

$$
\begin{aligned}
& \mathrm{g} / \mathrm{L}=\mathrm{ws} \cdot 10 \\
& \mathrm{~h}=(\mathrm{w} / 100-\mathrm{w}) \cdot 10^{*}
\end{aligned}
$$

但L、S は溶液の比重を示す。

\section{3. 実験式の算出}

篗者の一人（三次）㭠上記の Int. Crit. Table の值

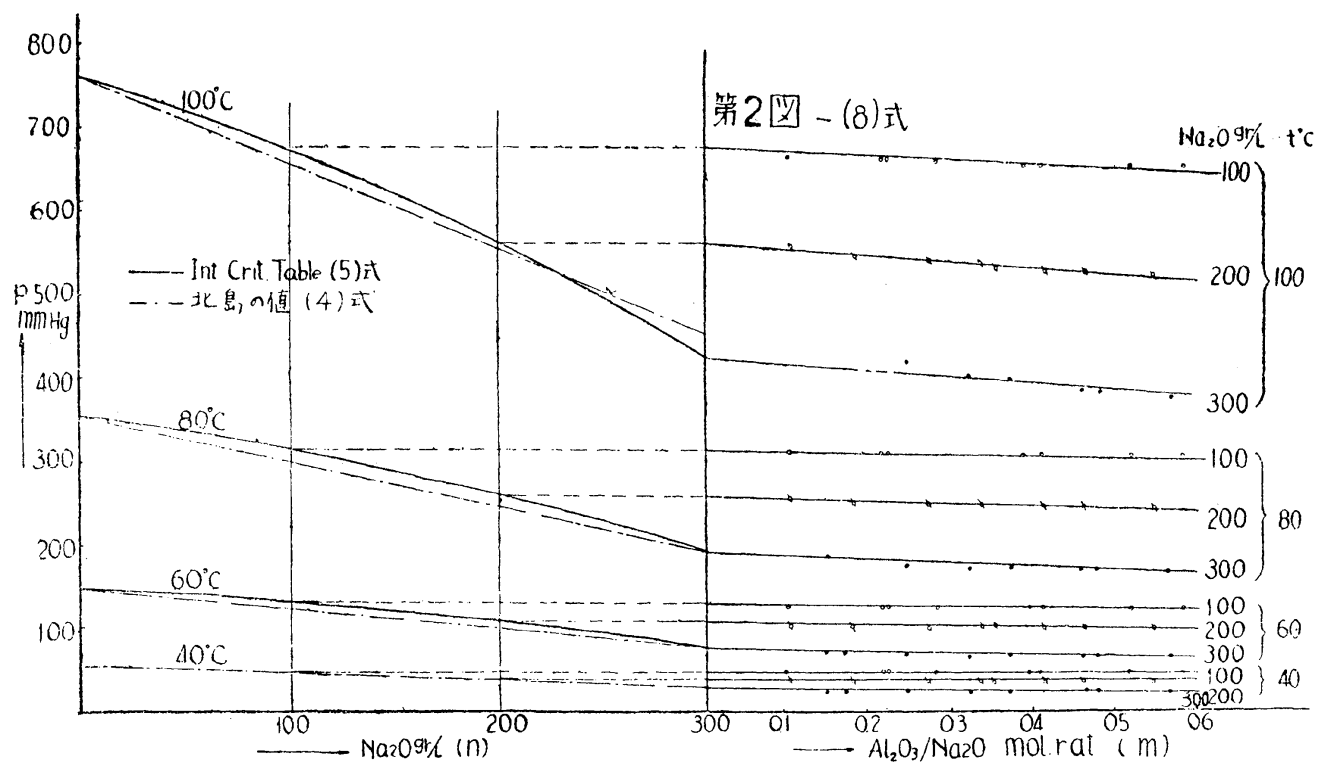

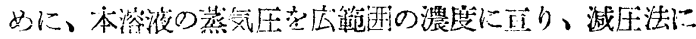
依り測定した。

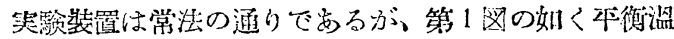

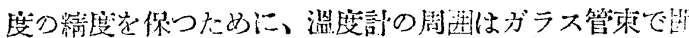
しである。

分析法は Wincliar 法友で Wander 法住り $\mathrm{HCl}$ 澱定で冰めた。

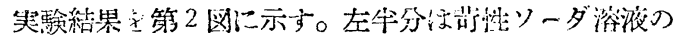

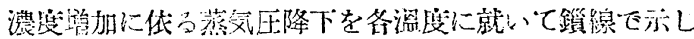

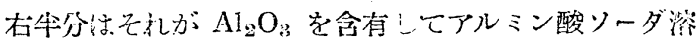

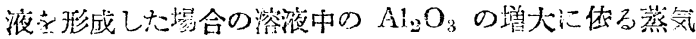

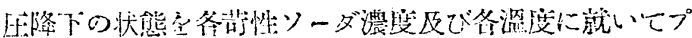
ロツトしてある。尽に見る蝴く蒴性りーダ、及びアルミ

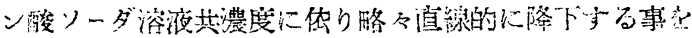
知る。
皮び北自の測定倠に就いて以下に速べる实験式在㖨めた 本采学相供加ら見ると $\mathrm{F}=\mathrm{C}+2-\mathrm{P}$ に於 $\mathrm{H}_{2} \mathrm{O}, \mathrm{Na}_{2}$ $\mathrm{O}, \mathrm{Al}_{2} \mathrm{O}$, の三成分系にあつては $\mathrm{F}=3$ となり、湍度皮

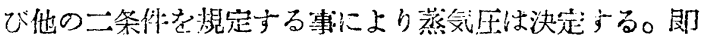

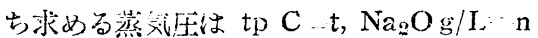

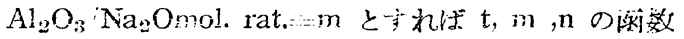
として求めら古る。

$$
P=f(t, m, n)
$$

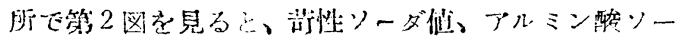

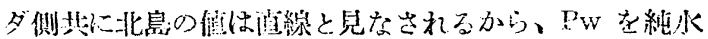

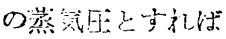

$$
(p) t=(p w+a n)(1+b m)=p w-
$$$$
\mathrm{xn}+\mathrm{ym}+\mathrm{znm}
$$

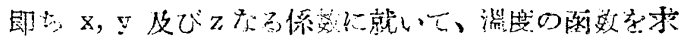
め机球い。 
所で純水の蒸気压に関しては M. Rankin が Nernst の簡略式より次式要求めている。

$\log \mathrm{Pw}=\mathrm{a}+\mathrm{b} / \mathrm{T}+\mathrm{C} \log \mathrm{T}$

然し、水の蒸気圧に関しては從来広範図に百り精测さ れているのた、その㬰测偲をそのままPwとしてとる事 にした。

(2) 式の xの算出 : -

北島の值に依り莮性ソーダ溶液の各溫度に於ける濃 度に依る蒸気压降下係数と溫度との対数をとると、きれ いな淔線を得る。之から $\mathrm{m}=0$ に就いて (4) 式を算出 した。

$$
\mathrm{n}=2.783 \mathrm{t} 2.783 \cdot 10^{-\mathrm{i}}
$$

所て之から水の活量を計算し、活量の溫度変化を求め ると第3 図の如く最小值齐生じて疑問を生ずる。そを Int. Crit. Table の值に基き計算すると、溫度上昇と共 に理想溶液に近づき合理的である。とから（2）式の形 式により求めると、 $\mathrm{n}$ に灀数が附随した曲線の式として (4) 式の変形が得られる。之を計算して (5) 式を得た $\mathrm{xn} \mathrm{x}^{\prime}=-4.02 \cdot 10^{-3} \mathrm{e}^{0.04317 \mathrm{t} \mathrm{n}^{1 \cdot 149}+3.72 \mathrm{t} \cdot 10^{-3}}$ 2.9t . 10-5

(4) 式及び (5) 式からの計算侹と Int. Cript. Table の值から內挿して求めた值とを比較すると第 1 表 の如くで (5) 式の精度を知る。

(2) 式の y の算出 : -

アルミン酸ソーダ溶液に於ける各 $\mathrm{Na}_{2} \mathrm{O}$ 濃度、各溫度 に於讨る $\mathrm{m}=0 \sim 10$ 間の蒸気压降下第 2 図上り求め、 之をプロツトしたのが第4図て、之から $n=0$ に於讨る 蒸㸚压降下を図上で外插して求め、その対数と溫度とを

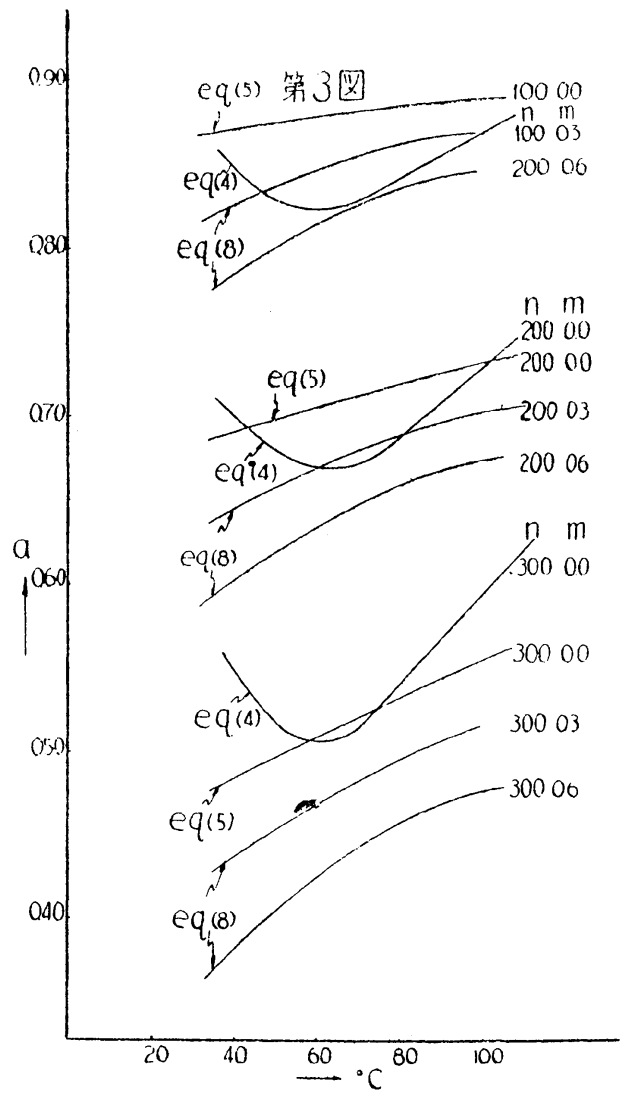

第 1 表

\begin{tabular}{|c|r|r|r|r|r|r|}
\hline$t^{\circ} \mathrm{C}$ & $\begin{array}{c}\mathrm{n} \\
(\mathrm{g} / \mathrm{L})\end{array}$ & $\mathrm{P}_{(4)}$ & $\mathrm{P}_{(5)}$ & Pc.t. & $\mathrm{P}_{(4)}-$ & $\mathrm{P}_{(5)}-$ \\
\multirow{3}{*}{40} & 100 & 47.2 & 479 & 48 & -0.8 & -0.1 \\
& 200 & 39.2 & 38.0 & 38 & +1.2 & 0.0 \\
& 300 & 313 & 26.7 & 27 & -4.3 & -0.3 \\
\hline \multirow{3}{*}{60} & 100 & 124.5 & 130.8 & 131 & -6.5 & -02 \\
& 200 & 99.8 & 104.9 & 107 & -7.2 & -2.1 \\
& 300 & 75.1 & 74.7 & 76 & -0.9 & -1.3 \\
\hline \multirow{3}{*}{80} & 100 & 300.1 & 313.0 & 313 & -12.9 & 0.0 \\
& 200 & 245.1 & 254.4 & 257 & -11.9 & -2.6 \\
& 300 & 190.1 & 188.2 & 190 & +0.1 & -0.8 \\
\hline \multirow{3}{*}{100} & 100 & 657.5 & 672.9 & 672 & -14.5 & +0.9 \\
& 200 & 555.0 & 555.4 & 557 & -2.0 & -1.6 \\
& 300 & 4525 & 421.9 & 422 & +30.5 & -0.1 \\
\hline
\end{tabular}

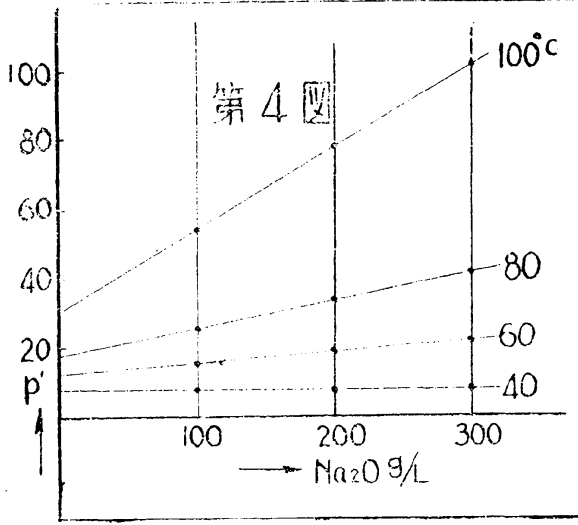

闵にすると谊線が求まる。とから yを算出すると (6) 式 の如し。

$$
\mathrm{y}=-3.24 \geq 0.0223 \mathrm{t}
$$

(2) 式の $z$ の算出 : -

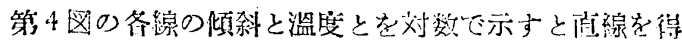
るので、そからてを溫度の函䘫として求められる。

$$
\left.Z=-6 t \quad 4.8 \cdot 10^{-11} \ldots \ldots \ldots \ldots \ldots \ldots \ldots \ldots \ldots .7\right)
$$

以上（2）、(5)、（6）及び (7) 式から求める垁験式は 次の如くなな。

$$
\begin{aligned}
& \mathrm{P}=\mathrm{Pw}-4.02 \mathrm{e}^{0.04317 \mathrm{t}} \text { 11 }{ }^{1.149}+3.7 \pm \mathrm{t} \cdot \\
& 10.3-2 \cdot 9 \mathrm{t}^{2} \cdot 10-5 \cdot 10^{-3}-3.24 \mathrm{me}^{0.0 \pm 23 \mathrm{t}} \\
& -6 \text { nnt } 4 \cdot 8 \cdot \cdot 10-11 \ldots \ldots . . . \ldots \ldots \ldots \text { (8) }
\end{aligned}
$$

但 $\mathrm{t}=4.0 \sim 100^{\circ} \mathrm{C}, \mathrm{n}=0-300 \mathrm{~s} / \mathrm{s}, \mathrm{m}=0 \sim 0.6$

（8）式の第 2 項まではmの項を含まず、击性ソーグ 㴶液の水蒸気王を示し、この精度に闒しては、前逝の邚 く第 1 表に挙げてあ!。文アルミン酸り一ダ浴液に咸す

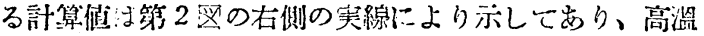
高濃度に於ける三三の実測健を除いてはよく一致してい

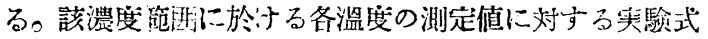
の標淮偏差を求めると第 2 表の好し。

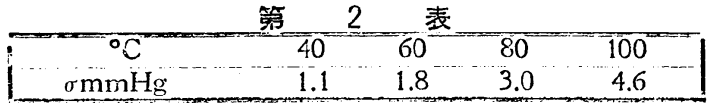

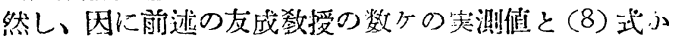

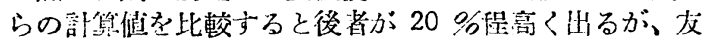

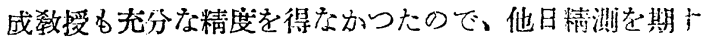

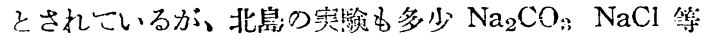
の不純物を溶液中!含有してい点及び分析法方涀在小 ら見ると、若干欠陷を持つている点から桨へて (8) 式の 第3 項及び第、項に就いては問題があり、少に閣しては 他日更に精確な式として求めて見たい。 